\title{
Application of upconversion luminescence in dye-sensitized solar cells
}

\author{
XIE GuiXiang, LIN JianMing, WU JiHuai*, LAN Zhang, LI QingHua, XIAO YaoMing, \\ YUE GenTian, YUE HaiFeng \& HUANG MiaoLiang
}

Engineering Research Center of Environment-Friendly Functional Materials, Ministry of Education, China; The Key Laboratory for Functional Materials of Fujian Higher Education, China; Institute of Material Physical Chemistry, Huaqiao University, Quanzhou 362021, China

\begin{abstract}
An upconversion luminescence powder $\mathrm{TiO}_{2:}\left(\mathrm{Er}^{3+}, \mathrm{Yb}^{3+}\right)$ is prepared by a hydrothermal method and used to fabricate dye-sensitized solar cell (DSSC). The $\mathrm{TiO}_{2}:\left(\mathrm{Er}^{3+}, \mathrm{Yb}^{3+}\right)$ powder undergoes upconversion luminescence, converting infrared light which the dye can not absorb into visible light with wavelengths of 510-700 nm which the dye can absorb, increasing the photocurrent of the DSSC. $\mathrm{TiO}_{2}:\left(\mathrm{Er}^{3+}, \mathrm{Yb}^{3+}\right)$ also acts as a p-type dopant, heightening the Fermi level of the oxide film, which increases the photovoltage of the DSSC. The best performance of the DSSC is found when the ratio of $\mathrm{TiO}_{2} /$ luminescence powder is $1 / 3$ in the luminescence layer. Under simulated solar irradiation of $100 \mathrm{~mW} \mathrm{~cm}{ }^{-2}$ (AM 1.5), the DSSC containing $\mathrm{TiO}_{2}:\left(\mathrm{Er}^{3+}, \mathrm{Yb}^{3+}\right)$ doping achieves a light-to-electricity energy conversion efficiency of $7.28 \%$ compared with $6.41 \%$ for the undoped DSSC.
\end{abstract}

dye-sensitized solar cell, upconversion luminescence, p-type doping

Citation: $\quad$ Xie G X, Lin J M, Wu J H, et al. Application of upconversion luminescence in dye-sensitized solar cells. Chinese Sci Bull, 2011, 56: 96-101, doi: $10.1007 / \mathrm{s} 11434-010-4115-2$

In 1991, Gratzel's group [1] reported a dye-sensitized solar cell with simple preparation procedure, low-cost, high efficiency and good stability, this new kinds of solar cell bring a revolutionary innovation for photoelectrichemical solar cell, and blaze a development direction for new generation's solar cells. The conversion efficiency of DSSC can reach up to $11 \%$ [2]. In DSSC, dyes N3 and N-719 often are used as photosensitized agents, and photoanodes together with $\mathrm{TiO}_{2}$ [1-5], therefore the solar light can be absorbed and transferred into electrical energy. The dye molecules can be regarded as an "electron pump", the driving energy of the pump comes from the solar light. The mainly absorption wavelength ranges for dyes N3 and N-719 are 290-700 nm [3-5]. About $43 \%$ of the radiant energy from the sun in the infrared region is not absorbed, which limits the sun energy conversion efficiency of DSSC. It is significant for transferring infrared light to visible light which the dyes can absorb and enhancing the light-to-

*Corresponding author (email: jhwu@ @qu.edu.cn) electricity conversion efficiency of DSSC.

Rare-earth-doped compounds have aroused extensive research as conversion luminescent mediums with potential applications in phosphors, display monitors, X-ray imaging, scintillators and solid-state lasers [6-10] because of their unique properties arising from their $4 \mathrm{f}$ electrons. However, using rare-earth-doped compounds for upconversion luminescence in DSSC has not been attempted so far.

In this paper, a luminescent $\mathrm{TiO}_{2}:\left(\mathrm{Er}^{3+}, \mathrm{Yb}^{3+}\right)$ powder is prepared by a hydrothermal method and used to fabricate a DSSC. $\mathrm{TiO}_{2:}\left(\mathrm{Er}^{3+}, \mathrm{Yb}^{3+}\right)$ behaves as an upconversion luminescence medium, transferring infrared light to visible light which the dye can absorb, enhancing the light-to-electricity conversion efficiency of the DSSC.

\section{Materials and methods}

\subsection{Materials and apparatus}

$\mathrm{TiO}_{2}$ nanoparticles (P25), butyl titanate, isopropanol, iodine, 
lithium iodide, polyglycol M-20,000, 4-tert-butyl-pyridine (TBP), Triton $\mathrm{X}-100$, ytterbium oxide $\left(\mathrm{Yb}_{2} \mathrm{O}_{3}\right)$ and erbium oxide $\left(\mathrm{Er}_{2} \mathrm{O}_{3}\right)$ were purchased from the Shanghai Chemical Agent Ltd., China (Analytical purity grade). The dye N-719 $\left[\mathrm{RuL}_{2}(\mathrm{NCS})_{2}, \mathrm{~L}=4,4\right.$ '-dicarboxylate-2,2'-bipyridine)] was purchased from Solaronix SA, Switzerland. Other reagents were from Shanghai Chemical Agent Ltd., China. Conducting glass with a fluorine-doped tin oxide layer (FTO glass) with a sheet resistance of $15 \Omega \mathrm{cm}^{2}$ was purchased from Hartford Glass Co. This was used as a substrate for precipitation of a $\mathrm{TiO}_{2}$ porous film and was cut into rectangles with a size of $2 \mathrm{~cm} \times 1.5 \mathrm{~cm}$. The mainly apparatus include in a stabilized power supply $\mathrm{Xe} / \mathrm{Hg}$ arc lamp (CHF-XM500W, Changtuo Scientific Ltd, Beijing, China) an electrochemical workstation (CHI660C, Shanghai Chenhua Device Company, China), an X-ray diffractometer (Bruker D8 Advance, Germany), an UV-Vis 2550 spectrophotometer and a Spectrofluorometer (FSP920, Edinburgh Instruments).

\subsection{Preparation of $\mathrm{TiO}_{2}$ nanocrystal colloid}

Using tetrabutyl titanate as precursor, a $\mathrm{TiO}_{2}$ nanocrystal colloid was prepared by the following procedure [11-14]. Tetrabutyl titanate $(10 \mathrm{~mL})$ was rapidly added to distilled water $(150 \mathrm{~mL})$, immediately forming a white precipitate. The system was stirred for $30 \mathrm{~min}$. The precipitate was filtered using a glass frit and washed three times with $100 \mathrm{~mL}$ of distilled water. The precipitate was added to an aqueous solution of nitric acid $\left(0.1 \mathrm{~mol} \mathrm{~L}{ }^{-1}, 100 \mathrm{~mL}\right)$ and stirred vigorously at $80^{\circ} \mathrm{C}$ until the slurry became a translucent bluewhite liquid. Thereinto $70 \mathrm{~mL}$ resultant colloidal suspension was autoclaved at $200^{\circ} \mathrm{C}$ for $12 \mathrm{~h}$ to form a white, milky slurry. The autoclaved $70 \mathrm{~mL}$ slurry was added to original blue-white liquid, adding $0.2 \mathrm{~g} \mathrm{TiO}_{2}$ powder (P25), stirring $30 \mathrm{~min}$, and then the second time hydrothermal treatment was conducted. The resultant slurry was concentrated to $1 / 5$ of its original volume, then PEG-20,000 (20 wt\%-30 wt $\%$ slurry) and a few drops of emulsification reagent Triton X-100 [12] were added to form a stable $\mathrm{TiO}_{2}$ nanocrystal colloid.

\subsection{Preparation of upconversion luminescence colloid}

A $\mathrm{TiO}_{2}:\left(\mathrm{Er}^{3+}, \mathrm{Yb}^{3+}\right)$ powder was prepared by the following process. Some of $\mathrm{Er}_{2} \mathrm{O}_{3}, \mathrm{Yb}_{2} \mathrm{O}_{3}$ and $\mathrm{LiOH}$ (as melt reagent) [15] were first dissolved in nitric acid (10 wt\%) to form a nitrate solution. Meanwhile, $10 \mathrm{~mL}$ of tetrabutyl titanate was added to $150 \mathrm{~mL}$ of vigorously stirred distilled water, immediately forming a white precipitate. The system was stirred for $30 \mathrm{~min}$. The precipitate was filtered using a glass frit and washed three times. The resulted precipitate was added into the nitrate solution, the $\mathrm{pH}$ of the mixed solution was adjusted to 1 by adding acetic acid $(10 \mathrm{~mL})$ and distilled water. The system was stirred at $80^{\circ} \mathrm{C}$ until a translucent blue-white colloid formed. The resultant colloid was autoclaved (filled less than $80 \%$ ) at $200^{\circ} \mathrm{C}$ for $12 \mathrm{~h}$ to form a white precipitate containing $\mathrm{Er}^{3+}$ and $\mathrm{Yb}^{3+}$. After the precipitate was vacuum dried at $100^{\circ} \mathrm{C}$, ground, calcined at $800^{\circ} \mathrm{C}$ for $2.5 \mathrm{~h}$ and cooled to room temperature, an upconversion luminescence powder was obtained.

The upconversion luminescence powder was added to the $\mathrm{TiO}_{2}$ colloid in different ratios and concentrated at $80^{\circ} \mathrm{C}$. then PEG-20000 (20 wt\%-30 wt\% slurry) and a few drops of Triton X-100 were added to form a stable upconversion luminescence colloid.

\subsection{Preparation of upconversion luminescence electrode}

Plastic adhesive tape was fixed on the four sides of the cleaned FTO conducting glass plate to restrict [13] the thickness of $10 \mu \mathrm{m}$ and the area of $1 \mathrm{~cm} \times 1 \mathrm{~cm}$ for the oxide film. The $\mathrm{TiO}_{2}$ colloid was dropped on the FTO glass plate using a scalpel. The resulting films were sintered at $450^{\circ} \mathrm{C}$ in air for 30 min to solidify the $\mathrm{TiO}_{2}$ film and delete organic impurity on the film, after cooling down to $80^{\circ} \mathrm{C}$, a normal $\mathrm{TiO}_{2}$ film was obtained. By using the same method, an upconversion luminescence layer with thickness of $4 \mu \mathrm{m}$ was covered on the $\mathrm{TiO}_{2}$ film. The resultant film was immersed in a $3 \times 10^{-4}$ mol L ${ }^{-1}$ solution of N-719 in absolute ethanol for $24 \mathrm{~h}$ to adequately absorb the dye. The dye-sensitized oxide film was washed with anhydrous ethanol and dried in moisture-free air in dark to give a dye-sensitized upconversion luminescence electrode.

\subsection{Characterization}

The phase and crystal structure of $\mathrm{TiO}_{2}:\left(\mathrm{Er}^{3+}, \mathrm{Yb}^{3+}\right)$ upconversion luminescence powders were checked with an X-ray diffractometer (Bruker D8 Advance, Germany) using $\mathrm{Cu}$ $\mathrm{K} \alpha$ radiation $(\lambda=1.5405 \AA)$ under $40 \mathrm{kV}, 40 \mathrm{~mA}$, and scan rate: $3 \% \mathrm{~min}$, scan range: $10^{\circ}-80^{\circ}$. UV-Vis absorption spectrum of dye was measured using a UV-Vis 2500 spectrophotometer (Shimadzu Corporation, Japan). The photoluminescence (emission and excitation) spectra of the upconversion luminescence powders were measured on a spectrofluorometer (FSP920, Edinburgh Instruments).

Photoelectric properties of the DSSCs were measured with an electrochemical workstation (CHI660C, Shanghai Chenhua Device Company, China) and a stabilized power supply $\mathrm{Xe} / \mathrm{Hg}$ arc lamp (CHF-XM-500W, Changtuo Scientific Ltd, Beijin, China).

\subsection{DSSC assemblage and photoelectric measurements}

A DSSC was assembled by injecting an electrolyte into the aperture between the $\mathrm{TiO}_{2}$ film electrode (anode electrode) and a Pt-coated counter electrode [14]. The electrolyte was consisted of $0.60 \mathrm{~mol} \mathrm{~L}^{-1}$ tetrabutyl ammonium iodide, $0.10 \mathrm{~mol}$ $\mathrm{L}^{-1} \mathrm{I}_{2}$, and $0.50 \mathrm{~mol} \mathrm{~L}^{-1}$ 4-tert-butyl-pyridine in acetonitrile.

Using the stabilized power supply $\mathrm{Xe} / \mathrm{Hg}$ arc lamp as a solar light simulator, controlling the incident light intensity 
$\left(P_{\text {in }}\right)$ of $100 \mathrm{~mW} \mathrm{~cm}^{-2}$, the short circuit density $\left(J_{\mathrm{SC}}, \mathrm{mA} \mathrm{cm}^{-2}\right)$ and open circuit voltage $\left(V_{\mathrm{OC}}, \mathrm{V}\right)$ were measured using the electrochemical workstation (CHI660C, Shanghai Chenhua Device Company, China). The fill factor $(F F)$ and the light-to-electricity conversion efficiency $(\eta)$ of the DSSC were calculated according to the following equations [16]:

$$
\begin{gathered}
\eta(\%)=\frac{V_{\text {max }} \times J_{\text {max }}}{P_{\text {in }}} \times 100 \%=\frac{V_{\mathrm{OC}} \times J_{\mathrm{SC}} \times F F}{P_{\text {in }}} \times 100 \%, \\
F F=\frac{V_{\text {max }} \times J_{\text {max }}}{V_{\mathrm{OC}} \times J_{\mathrm{SC}}},
\end{gathered}
$$

where $\left.J_{\max }(\mathrm{mA} \mathrm{cm})^{-2}\right)$ and $V_{\max }(\mathrm{V})$ are the current density and voltage at the point of maximum power output on the $J-V$ curves, respectively.

\section{Results and discussion}

\subsection{XRD patterns}

The XRD patterns of the $\mathrm{TiO}_{2}$ and $\mathrm{TiO}_{2}:\left(\mathrm{Er}^{3+}, \mathrm{Yb}^{3+}\right)$ powders are shown in Figure 1. Figure 1(a) shows that nearly all of the peaks correspond to the anatase phase (PDF No. 211272). Some of the rutile phase present in P25 is also observed. The anatase XRD peaks in Figure 1(a) are intense and well resolved, suggesting that the resultant $\mathrm{TiO}_{2}$ nanocrystals are highly crystalline. Nearly all of the anatase $\mathrm{TiO}_{2}$ changes to the rutile phase after calcination at $800^{\circ} \mathrm{C}$ for 2.5 (Figure 1(b)), because the signals after calcination are consistent with PDF card No. 65-0192. Figure 1(c) shows peaks resulting from the rutile phase of $\mathrm{TiO}_{2}$ in the $\mathrm{TiO}_{2}:\left(\mathrm{Er}^{3+}, \mathrm{Yb}^{3+}\right)$ powder as well as some pyrochlore phases from $\mathrm{Er}_{2} \mathrm{Ti}_{2} \mathrm{O}_{7}$ and $\mathrm{Yb}_{2} \mathrm{Ti}_{2} \mathrm{O}_{7}$ (marked with $\mathrm{p}$ ).

The average diameters $(D)$ of the particles can be calcu-

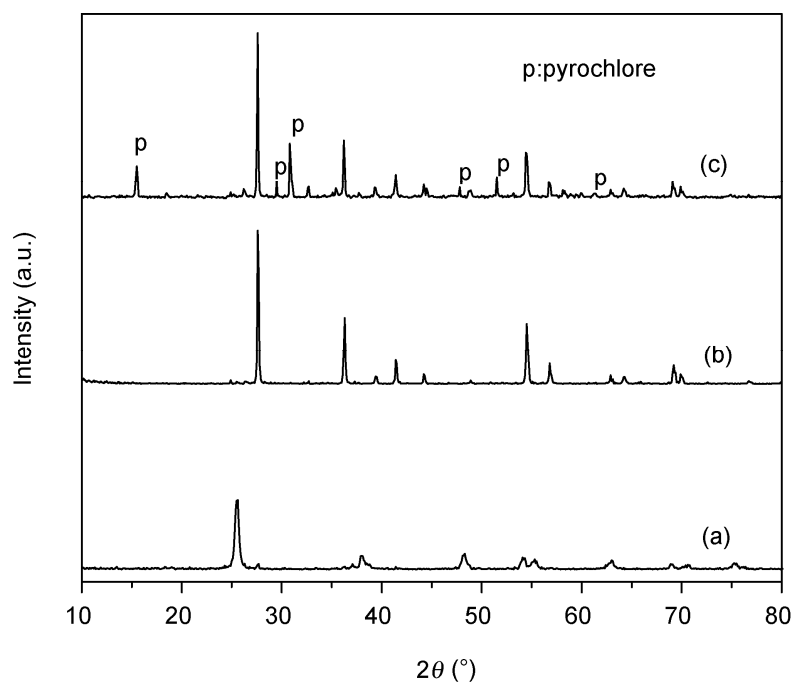

Figure 1 XRD patterns. (a) $\mathrm{TiO}_{2}$ nanocrystals after calcination at $450^{\circ} \mathrm{C}$ for $2.5 \mathrm{~h}$; (b) $\mathrm{TiO}_{2}$ nanocrystals after calcination at $800^{\circ} \mathrm{C}$ for $2.5 \mathrm{~h}$ and (c) $\mathrm{TiO}_{2}:\left(\mathrm{Er}^{3+}, \mathrm{Yb}^{3+}\right)$ powder. lated by the Scherrer formula [17]:

$$
D_{h k l}=\frac{k \lambda}{\beta \cos \theta}
$$

where $D_{h k l}$ is the particle size in the normal direction for $(h k l)$ crystal face. Here, the constant $K$ (depends on the particle shape, face index, $\beta$ and $\left.D_{h k l}\right)$ adopts 0.9 [14]. $\lambda(0.1540$ $\mathrm{nm})$ is the wavelength of the $\mathrm{Cu}-\mathrm{K} \alpha$ radiation, $\theta$ is the diffraction angle and $\beta$ is the full width at half-maximum (FWHM in radians).

According to Figure 1 and eq. (3), the apparent size $D$ of the $\mathrm{TiO}_{2}$ nanocrystals in Figure 1(a) and the upconversion luminescence powders in Figure 1(c) are $19 \mathrm{~nm}$ and $68 \mathrm{~nm}$, respectively. Compared with the diffraction peaks in curves (a) and (b), the intensity of diffraction peaks in curve (c) increase, indicating that the conversion luminescence powder has a higher crystallization and larger size, which the larger particles as light scattering points extend the light diffuse path, and enhance the incident photons capture efficiency [18]. Meanwhile, it is known that the refractive index of the anatase phase is lower than that of the rutile phase (anatase: 2.5 ; rutile: 2.7 ). Thus $\mathrm{TiO}_{2}:\left(\mathrm{Er}^{3+}, \mathrm{Yb}^{3+}\right)$ layer show a higher refractive index than undoped $\mathrm{TiO}_{2}$, which should help to increase light-to-electricity conversion efficiency of the DSSC.

\subsection{Excitation and emission spectra of $\mathrm{TiO}_{2}:\left(\mathrm{Er}^{3+}\right.$, $\mathbf{Y b}^{3+}$ )}

Figure 2(a) shows the excitation spectra of the $\mathrm{TiO}_{2}:\left(\mathrm{Er}^{3+}\right.$, $\mathrm{Yb}^{3+}$ ) powder. A strong, broad peak at $978 \mathrm{~nm}$ is observed. The band centered at $978 \mathrm{~nm}$ can be identified as the transition of $\mathrm{Yb}^{3+}$ from ${ }^{2} \mathrm{~F}_{7 / 2}$ to ${ }^{2} \mathrm{~F}_{5 / 2}$, indicating that the upconversion luminescence powder can effectively absorb the infrared light.

The luminescence spectra of the $\mathrm{TiO}_{2}:\left(\mathrm{Er}^{3+}, \mathrm{Yb}^{3+}\right)$ powder exhibits peaks in the green region from $510-570 \mathrm{~nm}$ and in the red region from 610-700 $\mathrm{nm}$ as shown in Figure 2(b). Upconversion fluorescence excitation can be readily observed with a $978 \mathrm{~nm}$ laser. The peaks centered at 521, 544 and $650 \mathrm{~nm}$ correspond to the $\mathrm{Er}^{3+}:{ }^{2} \mathrm{H}_{11 / 2} \rightarrow{ }^{4} \mathrm{I}_{15 / 2},{ }^{4} \mathrm{~S}_{3 / 2} \rightarrow$ ${ }^{4} \mathrm{I}_{15 / 2}$, and ${ }^{4} \mathrm{~F}_{9 / 2} \rightarrow{ }^{4} \mathrm{I}_{15 / 2}$ [19-22] transitions, respectively. These upconversion luminescences, especially in $544 \mathrm{~nm}$, are accorded with the absorption wavelength of the N-719. When doping the $\mathrm{TiO}_{2}:\left(\mathrm{Er}^{3+}, \mathrm{Yb}^{3+}\right)$ powder in the photoanode of DSSC, it will effectively enhance the light-to-electricity efficiency of DSSC.

Figure 3 shows the energy level diagram for $\mathrm{Er}^{3+}$ and $\mathrm{Yb}^{3+}$ codoped systems and upconversion luminescence process. The upconversion luminescence mechanism is shown as [20,22]: $\mathrm{Yb}^{3+}$ ions have a much larger absorption cross-section relative to that of $\mathrm{Er}^{3+}$ ions around $978 \mathrm{~nm}$, so $\mathrm{Yb}^{3+}$ ions are excited preferentially. $\mathrm{An}^{\mathrm{Er}^{3+}}$ ion can then be excited from the ${ }^{4} \mathrm{I}_{15 / 2}$ ground state to the ${ }^{4} \mathrm{I}_{11 / 2}$ excited state by energy transfer from an excited $\mathrm{Yb}^{3+}$ ion. $\mathrm{The}^{3+}$ ion is 

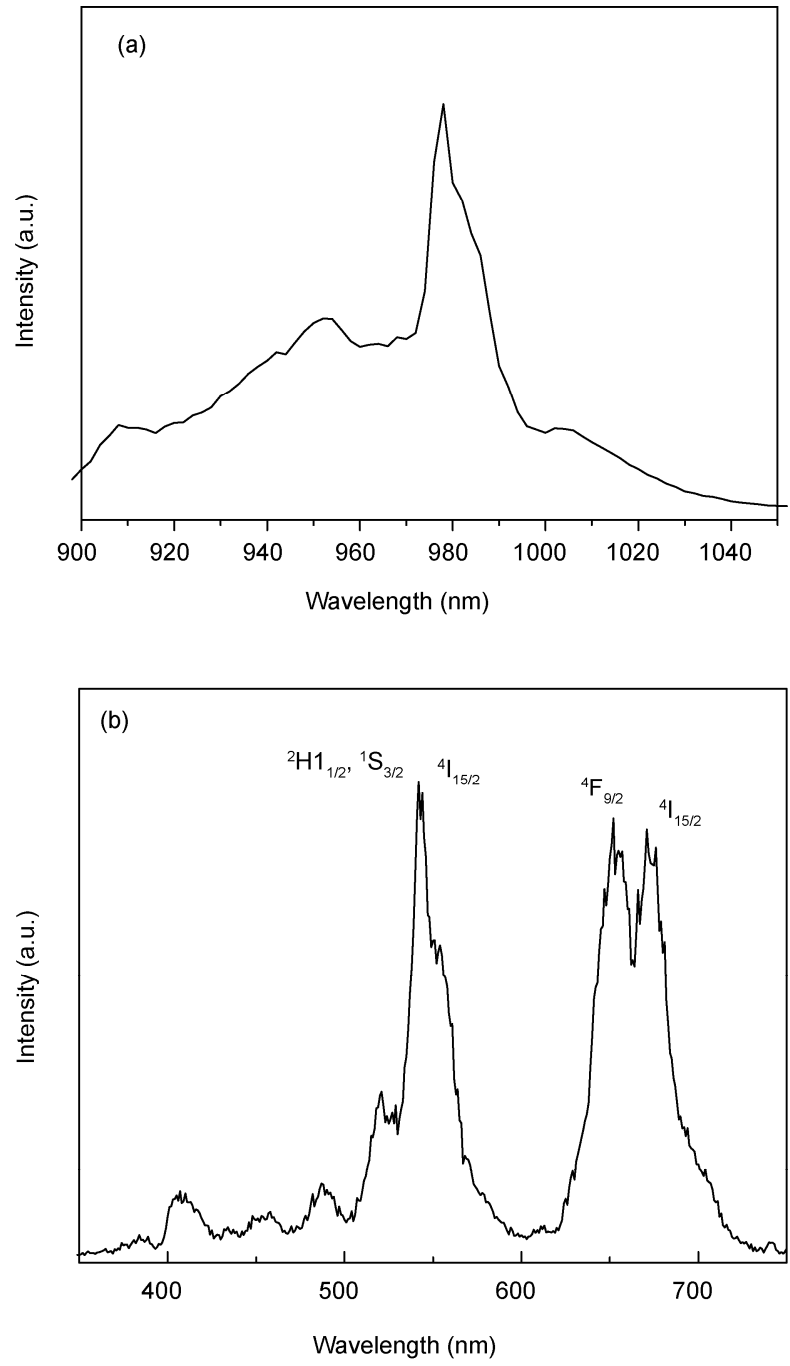

Figure 2 Excitation (a) and luminescence (b) spectra of $\mathrm{TiO}_{2}:\left(\mathrm{Er}^{3+}, \mathrm{Yb}^{3+}\right)$ powders excited with a laser at $978 \mathrm{~nm}$.

subsequently excited to the ${ }^{4} \mathrm{~F}_{7 / 2}$ state by absorbing energy from another $\mathrm{Yb}^{3+}$ ion. The $\mathrm{Er}^{3+}$ ion then decays nonradiatively to the ${ }^{2} \mathrm{H}_{11 / 2},{ }^{4} \mathrm{~S}_{3 / 2}$ and ${ }^{4} \mathrm{~F}_{9 / 2}$ levels. In addition, $\mathrm{Er}^{3+}$ ions in the ${ }^{4} \mathrm{I}_{11 / 2}$ excited state can decay nonradiatively to the ${ }^{4} \mathrm{I}_{13 / 2}$ level and be excited to the ${ }^{4} \mathrm{~F}_{9 / 2}$ level by absorbing a second photon, resulting in green light emission $(521 \mathrm{~nm}$ and $544 \mathrm{~nm} ;{ }^{2} \mathrm{H}_{11 / 2} \rightarrow{ }^{4} \mathrm{I}_{15 / 2}$ and ${ }^{4} \mathrm{~S}_{3 / 2} \rightarrow{ }^{4} \mathrm{I}_{15 / 2}$, respectively). Alternatively, the $\mathrm{Er}^{3+}$ can further relax and populate the ${ }^{4} \mathrm{~F}_{9 / 2}$ level leading to the red emission at $650 \mathrm{~nm}$ from the transition ${ }^{4} \mathrm{~F}_{9 / 2} \rightarrow{ }^{4} \mathrm{I}_{15 / 2}$.

\subsection{UV-Vis absorption spectrum}

The UV-Vis absorption spectrum of the dye-sensitized $\mathrm{TiO}_{2}$ electrode is shown in Figure 4. A strong, broad absorption band occurs from 290 to $700 \mathrm{~nm}$ with a maximum at about $385 \mathrm{~nm}$ and a shoulder at $528 \mathrm{~nm}$. It should be noted that the dye-sensitized $\mathrm{TiO}_{2}$ electrode cannot absorb light with wavelengths higher than $700 \mathrm{~nm}$. According to the discussion on excitation and luminescence spectra, addition of $\mathrm{TiO}_{2}$ :

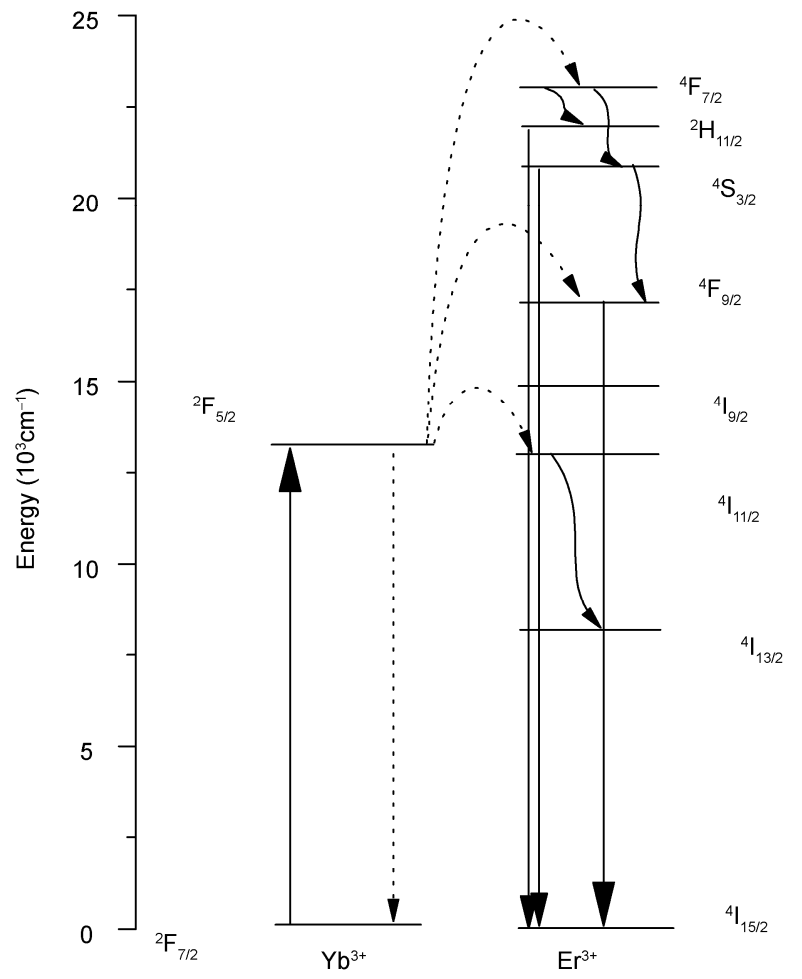

Figure 3 Energy levels of $\mathrm{Er}^{3+}$ and $\mathrm{Yb}^{3+}$ and upconversion transition pathways under 978-nm infrared excitation.

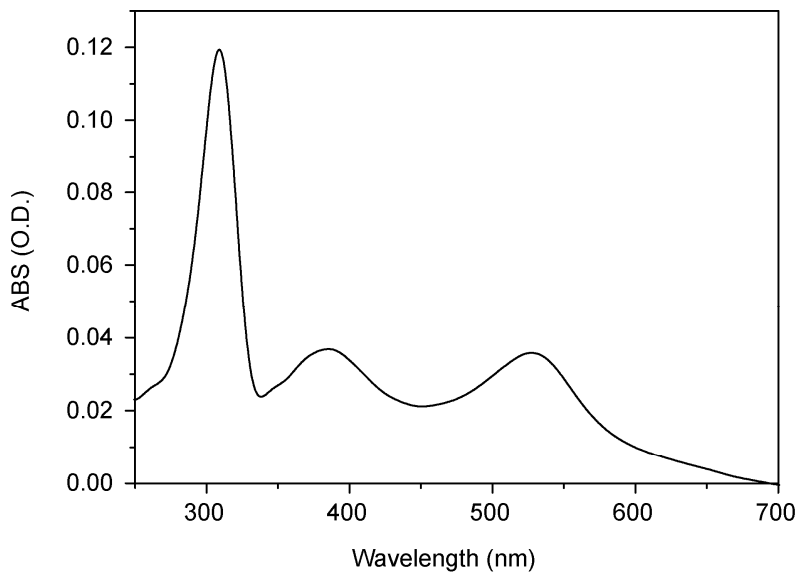

Figure 4 UV-Vis absorption spectrum of a dye-sensitized $\mathrm{TiO}_{2}$ electrode.

$\left(\mathrm{Er}^{3+}, \mathrm{Yb}^{3+}\right)$ powder into the $\mathrm{TiO}_{2}$ electrode should allow the infrared light with wavelength about $978 \mathrm{~nm}$ which the dye can not absorb transfers to the green light and the red light which the dye has a high absorption. Therefore, the more solar irradiation is absorbed by DSSC and the light-to-electricity conversion efficiency of the DSSC is increased.

\subsection{Influence of upconversion luminescence on the photoelectric properties of DSSC}

To investigate the effect of infrared irradiation on DSSCs, 
we used a filter stop to remove the light of wavelength less than $720 \mathrm{~nm}$. Figure 5 shows the photovoltaic characterization of the DSSCs with and without the upconversion luminescence powder under infrared irradiation of $60 \mathrm{~mW} \mathrm{~cm}^{-2}$. The DSSC lacking the upconversion luminescence powder possessed the photovoltaic parameters: $J_{\mathrm{SC}}=0.105 \mathrm{~mA}$ $\mathrm{cm}^{-2}, V_{\mathrm{OC}}=401 \mathrm{mV}, F F=0.560$ and $\eta=0.04 \%$. The DSSC containing the upconversion luminescence powder displays enhanced photovoltaic parameters: $J_{\mathrm{SC}}=0.248 \mathrm{~mA}$ $\mathrm{cm}^{-2}, V_{\mathrm{OC}}=561 \mathrm{mV}, F F=0.631$ and $\eta=0.146 \%$. The enhancement indicates that the upconversion luminescence layer can transfer infrared light to visible light which the N-719 dye can absorb effectively, increasing the harvested sunlight and improving the efficiency of the DSSC.

The photocurrent-voltage curves of the DSSCs with and without an upconversion luminescence powder under simulated solar light irradiation of $100 \mathrm{~mW} \mathrm{~cm}^{-2}$ (AM 1.5) are shown in Figure 6. Table 1 shows the influence of the amount of the luminescence powder on the photoelectric properties of the DSSCs. As the amount of the luminescence powder in the DSSC increases, $J_{\mathrm{SC}}$ increases and then decreases, and $V_{\mathrm{OC}}$ increases. The maximum efficiency of the DSSC is achieved when the mass ratio of $\mathrm{TiO}_{2} /$ luminescence powder is $1 / 3$ in the luminescence layer.

The increase in $J_{\mathrm{SC}}$ with the amount of the luminescence powder at low concentrations is because the luminescence powder absorbs infrared light $(978 \mathrm{~nm})$ which it transfers to visible light (510-700 nm), resulting in an increase in incident light harvest, photoinduced electrons in unit area, and $J_{\mathrm{SC}}$ in the DSSC. On the other hand, larger particle sizes in the upconversion luminescence layer extend the light transmission distance, improving the incident light harvest [23], and increasing the photocurrent. However, when $\mathrm{Er}^{3+}$ and $\mathrm{Yb}^{3+}$ are doped in $\mathrm{TiO}_{2}$, some crystal defects are present. The defects can capture photoinduced electrons and holes, leading to a decrease in photocurrent, especially in higher $\mathrm{Er}^{3+}$ and $\mathrm{Yb}^{3+}$ concentration. This explains why $J_{\mathrm{SC}}$ increases and then decreases as the amount of $\mathrm{TiO}_{2}:\left(\mathrm{Er}^{3+}\right.$, $\left.\mathrm{Yb}^{3+}\right)$ in the DSSC increases.

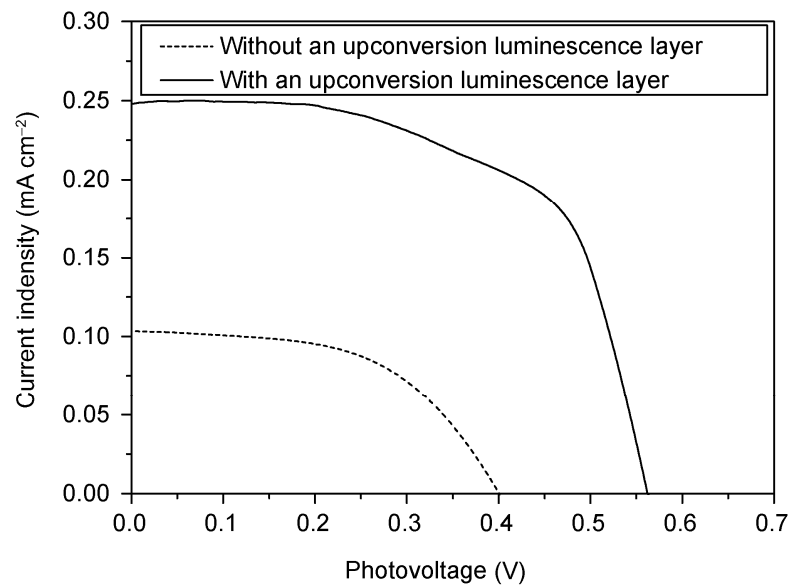

Figure 5 Photocurrent-voltage curves of the DSSCs with and without an upconversion luminescence layer under infrared irradiation.

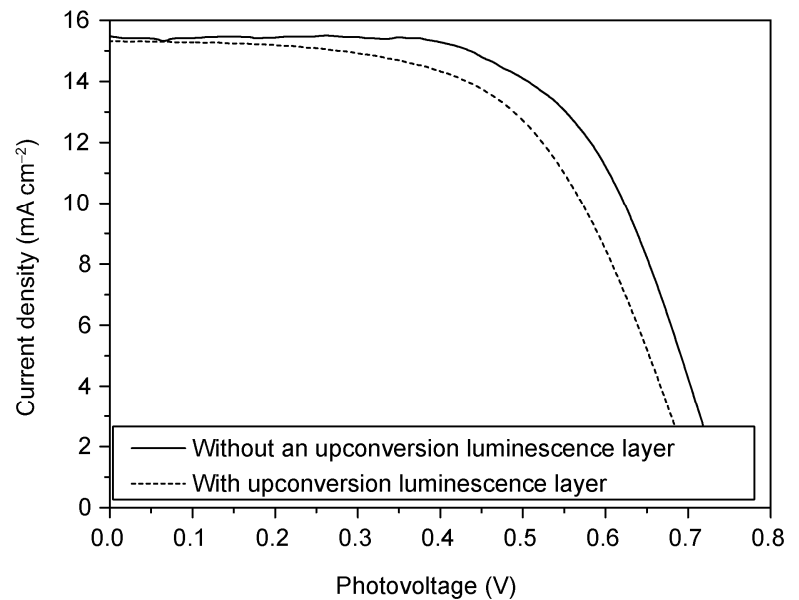

Figure 6 Photocurrent-voltage curves of DSSCs with and without an upconversion luminescence layer.

Table 1 Effects of an upconversion luminescence layer on the photoelectric properties of DSSCs

\begin{tabular}{ccccc}
\hline $\begin{array}{c}\mathrm{TiO}_{2} / \text { luminescence } \\
\text { powder (mass ratio) }\end{array}$ & $J_{\text {SC }}\left(\mathrm{mA} \mathrm{cm}^{-2}\right)$ & $V_{\mathrm{OC}}(\mathrm{V})$ & $F F$ & $\eta(\%)$ \\
\hline $1: 0$ & 15.40 & 0.717 & 0.580 & 6.41 \\
$1: 1$ & 15.57 & 0.718 & 0.598 & 6.68 \\
$1: 2$ & 15.92 & 0.724 & 0.588 & 6.81 \\
$1: 3$ & 15.45 & 0.748 & 0.629 & 7.28 \\
$1: 4$ & 13.35 & 0.799 & 0.611 & 6.52 \\
$1: 5$ & 10.91 & 0.817 & 0.633 & 5.64 \\
\hline
\end{tabular}

According to Gratzel, $V_{\mathrm{OC}}$ corresponds to the potential difference between the Fermi level of the electrons in the oxide film and the redox potential of the electrolyte [1,2]. When $\mathrm{Er}^{3+}$ and $\mathrm{Yb}^{3+}$ ions substitute $\mathrm{Ti}^{4+}$ ion lattice sites in $\mathrm{TiO}_{2}$, similar to $\mathrm{Si}$ semiconductors, i.e., p-type doping, the energy level of the oxide film is elevated, resulting in an increase of $V_{\mathrm{OC}}$. In our experiments, the electrolyte is the same so it is unsurprising that $V_{\mathrm{OC}}$ increases as the amount of $\mathrm{Er}^{3+}$ and $\mathrm{Yb}^{3+}$ ions increase. When the mass ratio of $\mathrm{TiO}_{2} / \mathrm{TiO}_{2}:\left(\mathrm{Er}^{3+}, \mathrm{Yb}^{3+}\right)$ is $1 / 5$ in the luminescence layer, $V_{\mathrm{OC}}$ reaches $0.817 \mathrm{~V}$. This value is higher than that of other DSSCs with the same structure, showing significance of p-type doping for enhancing the photovoltage of DSSCs.

Comprising $J_{\mathrm{SC}}, V_{\mathrm{OC}}, F F$ and $\eta$, when the mass ratio of $\mathrm{TiO}_{2} / \mathrm{TiO}_{2}:\left(\mathrm{Er}^{3+}, \mathrm{Yb}^{3+}\right)$ is $1 / 3$ in the upconversion luminescence layer, the light-to-electricity conversion efficiency of the DSSC reaches $7.28 \%$, which is an improvement of $13.6 \%$ compared with the DSSC not doped with rare-earth ions.

\section{Conclusions}

In summary, a $\mathrm{TiO}_{2}:\left(\mathrm{Er}^{3+}, \mathrm{Yb}^{3+}\right)$ powder was synthesized using a hydrothermal method. The powder was used to fabricate an oxide film in the DSSCs. The rare-earth oxide undergoes upconversion luminescence, transferring infrared light (DSSC can not absorb) into visible light with wave- 
lengths of 510-700 nm (DSSC can absorb), enhancing the photocurrent of the DSSC. As a p-type dopant, the rareearth oxide increases the Fermi level of the oxide film and the photovoltage of DSSC. The highest efficiency of the DSSC is reached when the mass ratio of $\mathrm{TiO}_{2} / \mathrm{TiO}_{2}:\left(\mathrm{Er}^{3+}\right.$, $\mathrm{Yb}^{3+}$ ) is $1 / 3$ in the upconversion luminescence layer. Under a simulated solar light irradiation of $100 \mathrm{~mW} \mathrm{~cm}^{-2}$ (AM 1.5), the DSSC containing $\mathrm{TiO}_{2} / \mathrm{TiO}_{2}\left(\mathrm{Er}^{3+}, \mathrm{Yb}^{3+}\right)$ doping achieved a short-circuit current density of $15.45 \mathrm{~mA} \mathrm{~cm}$, an open-circuit voltage of $0.748 \mathrm{~V}$ and a light-to-electricity conversion efficiency of $7.28 \%$, which is enhanced by $13.6 \%$ compared with the DSSC lacking the luminescent layer. The present findings demonstrate the feasibility of rare-earth doping in DSSCs for providing an effective way to improve their sunlight conversion efficiency.

This work was supported by the National High Technology Research and Development Program of China (2009AA03Z217) and the National Natural Science Foundation of China (90922028, 50842027).

1 O'Regan B, Gratzel M. A low-cost high-efficiency solar cell based on dye-sensitized colloidal $\mathrm{TiO}_{2}$ films. Nature, 1991, 353: 737-740

2 Gratzel M. Solar energy conversion by dye-sensitized photovoltaic cells. Inorg Chem, 2005, 44: 6841-6851

3 Gratzel M. Engineering of a novel ruthenium sensitizer and its application in dye-sensitized solar cells for conversion of sunlight into electricity. Inorg Chem, 2005, 44: 178-180

4 Lee S A, Abrams N M, Hoertz P G, et al. Compling of titania inverse opals to nanocrystalline titania layers in dye-sensitized solar cells. J Phys Chem B, 2008, 112: 14415-14421

5 Nazeeruddin M K, Kay A, Rodicio I, et al. Conversion of light to electricity by cis-bis (2, 2'-bipyridyl-4, 4'-dicarboxylate) ruthenium (II) charge-transfer sensitizers $\left(\mathrm{X}=\mathrm{Cl}^{-}, \mathrm{Br}^{-}, \mathrm{I}^{-}, \mathrm{CN}^{-}\right.$, and $\left.\mathrm{SCN}^{-}\right)$on nanocrystalline $\mathrm{TiO}_{2}$ electrodes. J Am Chem Soc, 1993, 115: 63826390

6 Wang W N, Widiyastuti W, Ogi T, et al. Correlations between crystallite/particle size and photoluminescence properties of submicrometer phosphors. Chem Mater, 2007, 19: 1723-1730

7 Yi G S, Lu H C, Zhao S Y, et al. Synthesis, characterization, and biological application of size-controlled nanocrystalline $\mathrm{NaYF}_{4}:(\mathrm{Yb}, \mathrm{Er})$ infrared-to-visible up-conversion phophors. Nano Lett, 2004, 4: 2191 $-2196$

8 Wu G S, Zhang L, Cheng B C, et al. Synthesis of $\mathrm{Eu}_{2} \mathrm{O}_{3}$ nanotube arrays through a facile sol-gel template approach. J Am Chem Soc,
2004, 126: 5976-5977

9 Lu H C, Yi G S, Zhao S Y, et al. Synthesis and characterization of multi-functional nanoparticles possessing magnetic, up-conversion fluorescence and bio-affinity properties. J Mater Chem, 2004, 14: 1336-1341

10 Sivakumar S, Veggel F, Raudsepp M. Bright white light through up-conversion of a single NIR source from sol-gel-derived thin film made with $\mathrm{Ln}^{3+}$-doped $\mathrm{LaF}_{3}$ nanoparticles. J Am Chem Soc, 2005, 127: $12464-12465$

11 Wu J H, Hao S C, Lin J M, et al. Crystal morphology of anatase titania nanocrystals used in dye-sensitized solar cell. Cryst Growth Des, 2008, 8: 247-252

12 Lan Z, Wu J H, Lin J M, et al. Influence of molecular weight of PEG on the property of polymer gel electrolyte and performance of quasisolid-state dye-sensitized solar cells. Electrochim Acta, 2007, 52: 6673-6678

13 Hao S C, Wu J H, Fan L Q, et al. The influence of acid treatment of $\mathrm{TiO}_{2}$ porous film electrode on photoelectric performance of dye-sensitized solar cell. Sol Energy, 2004, 76: 745-750

14 Wang P, Zakeeruddin S, Comte P, et al. Enhance the performance of dye-sensitized solar cells by co-grafting amphiphilic sensitizer and hexadecylmalonic acid on $\mathrm{TiO}_{2}$ nanocrystals. J Phys Chem B, 2003, 107: 14336-14341

15 Pang T, Cao W H. Up-conversion luminescence by yttrium tantalate doping $\mathrm{Er}^{3+}$ and co-doping $\mathrm{Er}^{3+}-\mathrm{Y}^{3+}$ (in Chinese). Chinese Sci Bull, 2007, 52: 2226-2229

16 Gratzel M. Perspectives for dye-sensitized nanocrystalline solar cells. Prog Photovoltaic Res Applic, 2000, 8: 171-185

17 Ito S, Yoshida S, Watanabe T. Fabrication and characterization of meso-macroporous anatase $\mathrm{TiO}_{2}$ films. J Chem Soc Jap, 2000, 73: 1933-1938

18 Sarmimala H, Peter N, Carmen V, et al. Scattering spherical voids in nanocrystalline $\mathrm{TiO}_{2}$-enhancement of efficiency in dye-sensitized solar cells. Chem Commun, 2005: 2011-2013

19 Chen S Y, Ting C C, Hsieh W F. Comparison of visible fluorescence properties between sol-gel derived $\mathrm{Er}^{3+}-\mathrm{Yb}^{3+}$ and $\mathrm{Er}^{3+}-\mathrm{Y}^{3+}$ co-doped $\mathrm{TiO}_{2}$ films. Thin Solid Films, 2003, 434: 171-177

20 Boyer J, Cuccia L A, Capoianco J A. Synthesis of colloidal upconverting $\mathrm{NaYF}_{4}: \mathrm{Er}^{3+} / \mathrm{Yb}^{3+}$ and $\mathrm{Tm}^{3+} / \mathrm{Yb}^{3+}$ monodisperse nanocrystals. $\mathrm{J}$ Am Chem Soc, 2007, 7: 847-852

21 Li C X, Quan Z W, Yang P P, et al. Shape-controllable synthesis and up-conversion properties of lutetium fluoride (doped with $\mathrm{Yb}^{3+} / \mathrm{Er}^{3+}$ ) microcrystals by hydrothermal process. J Phys Chem C, 2008, 112: 13395-13404

22 Yu H, Shang Q K, Wang H D, et al. Up-conversion luminescence properties of $\mathrm{Er}^{3+}$ and $\mathrm{Yb}^{3+}$ co-doped $\mathrm{TiO}_{2}$ nanopowders. J Mol Sci, 2007, 23: 118-122

23 Liu Y, Shen H, Huang X R, et al. A new improved structure of dye-sensitized solar cells with reflection film. Chinese Sci Bull, 2006, 51: 369-373

Open Access This article is distributed under the terms of the Creative Commons Attribution License which permits any use, distribution, and reproduction in any medium, provided the original author(s) and source are credited. 